internal hæmorrhage, and was greatly surprised to find, on examination through the abdominal parietes, that the womb was already contracted firmly to its usnal post-partum dimensions. There was no flooding whatever, internal or external. This alarming state of exhaustion, \&c., continued with little variation or attempt at reaction for nearly three hours, notwithstanding the most energetic and persevering measures were put in force. So intense indeed was the collapse that the attendants more than once considered her dead, and could with difficulty be persuaded that she was not the victim of flooding. I shall not, of course, enter into any detail of the treatment, which was conducted on general principles. After a long while the circulation became re-established, and the senses restored. Recovery was gradual.

The remarkable feature in this case is the excessive nervous prostration, so disproportionate both to the length and severity of the previous labour, and to the amount of hæmorrhage. The case appears to bear some analogy to that of the Princess Charlotte: as regards-first, the irregular contraction of the nterus; secondly, the amount of blood lost externally; and, thirdly, the disproportionate collapse. It differs from that of the unfortunate princess-first, in the duration and severity of the previous labour which extended over a period of fifty hours, dating from the discharge of the liquor amnii; and, secondly, in the quantity of blood in the uterus, revealed by the autopsy.

How are we satisfactorily to account for these unlooked-for contre-temps? - these fearful and sudden conditions of exhaustion of the norvous centres, so alarming and so very likely to be attended with a fatal result? The labour was only about twenty-two hours' duration, and, as has been above said, the pains were of average character. I have witnessed many thirty-six and forty hours' labours, and far more severe, followed by scarcely noticeable depression. The history of the patient sheds little or no light on the case. She was healthy and tolerably robust, not hysterical, nor subject to syncope or nervous seizures of any kind. Nor could $I$ ascertain the pre-existence of mental anxiety from any cause. The origin of the seizure, whatever it was, was from a purely physical, not a psychical, source.

Kensal Town, June, 1853.

\section{INJURY TO THE HEAD; DEPRESSION OF THE SKULL; RECOVERY.}

Bx RICHARD BRAMWELL, EsQ., M.R.C.S.E., L.S.A., Sussex.

J. B-, aged forty, farm-labourer, through some mis chance, whilst lowering a cask of porter into a cellar, got his head between it and a neighbouring wall, the result of which was that a cleanly-cut wound, three-quarters of an inch wide, and extending from the middle of the orbital arch backwards to the upper margin of the squamous portion of the temporal bone, was found on the left side of the head. On my arrival, which was in about an hour after the accident, found the loss of blood considerable, though not serious. Many small masses of brain, the united volume of which might be represented by that of a pullet's egg, had escaped from the wound. The man was comatose, but not perfectly so, being capable of answering questions when sharply roused, but immediately relapsing and breathing stertorously when left to himself. There had been some vomiting; the ejecta contained no blood. The pupils were dilated and sluggish, but not irregular. The pulse small, weak, and rather slow; the extremities somewhat cold. There was no paralysis of any part of the body, unless of the irides and the muscles of the soft palate, as indicated by their imperfectly-performed functions. On examining the wound, $I$ found bone, corresponding in extent with the lesion of the scalp, had been depressed and detached, and from the bevilled edges of the broken portions, it was evident that the inner table had been fractured to a greater extent than the outer.

This circumstance rendered the effective application of the elevator impossible without the further removal of bone, I therefore took this step, with the aid of a trephine, and removed a semicircle, the base of which corresponded to the centre of the upper margin of the fracture. After this proceeding, the raising and abstraction of the detached portion were sufficiently easy. The man now became quite sensible, and the stertor entirely disappeared; the pulse also rose, but the pupils were in much the same state as before.

The wound was brought together with half-a-dozen stitches and some straps. In two days the sutures were removed, and the wound found healed in three-fourths of its extent.
The man continued to get well, never having had an untoward symptom since the operation, with the exception that vision was double for some six or seven weeks, when the eye of the injured side was used either by itself, or with its fellow. There was nothing to be remarked in the physical condition of the organs; the pupils recovered their normal activity in a few days, and the functional derangement has now (three months from the accident) disappeared.

This case is instructive as exhibiting the uncertain indication of the symptoms ascribed respectively to concussion and compression, inasmuch as, according to the general notion, some of them must be referred to the one lesion, some to the other, whilst those proper to the former predominated; yet that concussion had little share in their production is evident, from their total subsidence on removal of the pressure. Convulsion also, so generally looked upon as a usual attendant upon laceration of the brain, was entirely wanting, showing that this viscus may sustain immense injury, even rupture and loss of substance, without producing any appreciable result. The almost entire absence of paralysis, also, will be remarked in such a case.

The next thing is the double vision. This circumstance was not discovered at the time of the accident; and from the complete occlusion of the eye, resulting from the tumefaction of its lids, which came on a few hours after the accident, its existence was not discovered for some days. The question arises-What was the cause? For my own part, I believe it to have been pressure; not that, however, which was produced by the depressed bone, for the obvious reason that it was not perceived until after the bone had been removed, but rather of a clot of blood impinging immediately upon the optic nerve, and probably in front of the commissure. The formation of such a clot, on the setting in of reaction, is not unlikely; and the gradual disappearance of the visual derangement would accord with its absorption, while the fact of the right eye performing its office correctly would point to the seat of pressure.

The practical lesson deduced is, that we cannot generally be quite certain whether a given case is one of concussion or compression, or whether a combination of both; and that our course should be shaped accordingly.

Mayfield, Sussex, June, 1853 .

\section{OPERATION FOR KNOCK-KNEES. To the Ealitor of THE Lancet.}

SIR, - The following case of operation for knock-knees is reported by Dr. Mayer, of the Orthopædic Hospital at Würzburg, in the proceedings of the Medical Society of that place, (lately published,) and seems well worth recording in your pages.

Your most obedient servant,

Knightsbridge, April, 1853 .

F. A. B. Bonney.

John $\mathrm{H}-\longrightarrow$, a strong and healthy-looking boy of fifteen, son of a baker, and employed in his father's business, was found, on admission into the Orthopædic Hospital at Würzburg, to have the right leg diverging about seven inches, and the left about eight, from the direction of the corresponding thigh, as seen in the first figure of the accompanying sketch.

On the 14th of Angust, 1851, the lad having been put under the influence of chloroform, Dr. Mayer made an incision beginning three-quarters of an inch below the insertion of the ligamentum patellæ, and curving downwards so as nearly to surround the front and inner (or mesial) side of the head of the tibia. He then turned the flap upwards, and divided the periosteum in the line of the first incision, and afterwards, with Heine's cutting-needle, separated the periosteum from the outer and posterior surface of the tibia, so as to prepare for the use of the saw. To protect the soft parts in that situation during the sawing, a strip of watch-spring, about half an inch wide, was introduced between the denuded bone and the periosteum. Dr. Mayer then, with a round saw, made two incisions converging towards the posterior part of the tibia, and meeting about a line and a half from the surface, without therefore quite cutting the bone in two. The wedge thus excised was about five lines thick at its base, and was easily removed by forceps. The wound was cleared of bone-dust by forcible injections of cold water, after which, through the flexibility of the remaining isthmus of the tibia and the mobility of the fibula, no difficulty was found in bringing the cut surfaces of bone into close apposition. The outer wound was brought together with the greatest accuracy by needles and ligatures, (as for hare-lip,) the hæmorrhage 
being quite inconsiderable. The leg was then put into one of Boyer's hollow splints, used for fracture of the patella.

Half an hour after the operation, as, through the perfect apposition of the divided parts, no discharge of any kind was visible, the wound was covered with a thick layer of collodium, and upon this drying the ligatures and needles were removed. The traumatic reaction was very slight, and on the fourth day the external wound (five inches long) had perfectly united. The leg was now left quiet in the splint for twentythree days, when Dr. Mayer had the pleasure of finding that the incised surfaces of bone had united also. The next day the patient was allowed to walk in his room with crutches, and $a$ few days afterwards in the garden without any artificial support whatever.

On the 3rd of October the other leg was operated on in the same manner and with the same success. He left the hospital, free from deformity, and with a firm and natural gait, on the $19 \mathrm{th}$ of November.

Fia. 1.

FIG. 2.
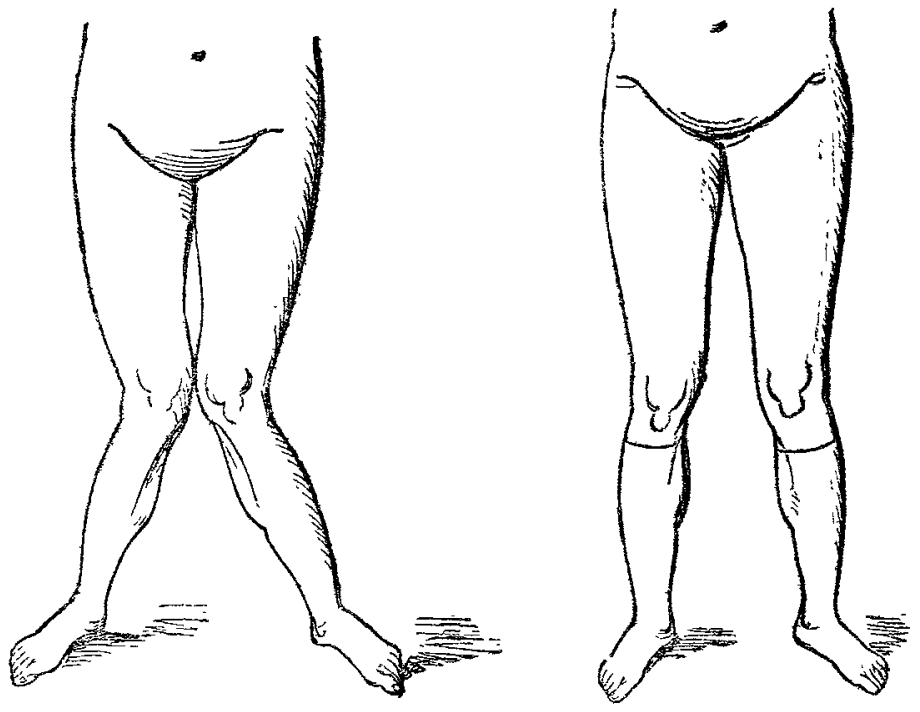

A Aníror

OF THE PRACTICE OF

\section{MEDICINE AND SURGERY IN THE \\ HOSPITALS OF LONDON.}

Nulla est alia pro certo noscendi via, nisi quam plurimas et morborum, et dissectionum historias, tum aliorum proprias, collectas habere et inter se comparare.-Morgagni, De Sed, et Caus, Morb., lib.14. Procemium.

\section{CASES OF AFFECTION OF THE KNEE-JOINT.}

1. St. Thomas's, under the care of Mr. SouTh.

2. GuY's

3. ST. BARThoLONEW's "

Ditto

Ditto

King's Collage

,

5. MrDDLesex

6. ST. GEORGE's

Ditto

Ditto

7. St. Mary's

8. Charing Cross

\section{Mr. Birkete}

Mr. Stanley.

Mr. LAWRENCE.

Mr. LLOYD.

Mr. Henry Lee.

Mr. SHA w.

Mr. JoHnson.

Mr. HAwrins and

Mr. HewetT.

Mr. Haweins.

Mr. Coulson.

Mr. AverY.

Mr. ADAMS

Mr. Cainds.

9. London
10. Metropolttan FreE "

Wr have now run through a certain number of cases of affection of the knee-joint, some of which present features of great interest. Those which we are this day putting upon record, and which almost conclude the series, are likewise replete with points of practical utility, and will doubtless be read with some advantage. The first case to which we beg to draw attention begins a series of facts collected in the hospitals of London, which facts illustrate morbid alterations in

the knee-joint, resulting from contiguity with diseased textures. The table has been re-arranged, so as to place the cases of analogous nature in immediate succession.

\section{KING'S COLLEGE HOSPITAL}

Fracture of the Patella, followed by Suppuration of the Kneejoint; Death; Autopsy.

(Under the care of Mr. HENRY LEE.)

JoHN $\mathrm{H} \longrightarrow$, aged thirty-seven, a stout, plethoric man, who has much indulged in drinking, and is a pastry-cook by trade, was admitted September, 1852.

Six months before admission the man snapped the patella transversely on the right side, in the act of throwing a skittleball. For this injury he went to St. Bartholomew's Hospital, where he remained three months. The fragments were after that time only half an inch from each other, and the patient able to walk fairly. A month after this, he slightly hurt the knee again; but the injury was so trifling that he was as well as usual in a week's time.

On September 17,1852 , three days before admission, the patient was attacked at two o'clock in the morning with a fit of shivering, which lasted until the middle of the day. It should be mentioned that ever since the first accident he had experienced a sense of tightness in the popliteal space; this uneasiness, he states, left him when the shivering came on. As soon as the rigors had ceased, the patient began to feel some pain in the injured knee, and on examining it, he found that it was swollen, red, and tender on pressure.

By the advice of a surgeon leeches were applied above the patella, and a blister on either side of the joint. This, however, gave no relief, and up to the time of his admission into the hospital the man continued to get worse. His mind had been wandering, and even on his reception he complained of a sense of confusion coming over him at times for a few minutes.

Shortly after the patient's admission, the knee being much swollen, and fluctuation easily discernible at the side, an incision was made on either side of the joint by Mr. Lee, and about three ounces of thin purulent matter escaped from an abscess situated between the fractured ends of the patella.

On the third day the knee was more swollen and red, and on passing a probe into the wound on the inner side of the joint, some clear fluid exuded. This opening was then extended towards the back of the knee for about two inches, and downwards for about one inch further.

On the following day the skin over the joint was of a deep. red colour, and the parts around much swollen; there was considerable tension about the wound, and on introducing the finger into the latter, the lower part of the inner condyle was distinctly felt, as also the rough exposed surfaces of the patella. Both the incisions were then enlarged, and a quantity of purulent matter escaped.

On the fifth day the swelling and redness had much subsided, but the patient remained in a very precarious state for the next eleven days; the wounds discharged profusely, and he had several shivering fits. Mr. Lee had him then placed under the influence of chloroform, and made an incision on the inner side of the upper part of the leg, from which a great quantity of pus escaped.

For the next few days the patient suffered repeated rigors, and Mr. Lee made more incisions in the leg, for the freer evacuation of the matter. But the man did not rally, and died October 16th, three days after this operative measure, and twenty-six days after admission.

Post-mortem Examination.-The body was loaded with fat and the patella broken transversely, the fragments being about half an inch apart. From the apex of the lower fragment a small piece was detached and necrosed; the cartilages were in several places absorbed, both on the articular surfaces of the femur and tibia; the crucial ligaments destroyed, and extensive suppuration between the hamstring muscles, the soleus, and gastrocnemius had taken place. The femoral vein appeared healthy, its lining membrane was not discoloured but at the junction of the profunda vein was some whitish matter, which Mr. Lee judged to be softened fibrine. In the lungs there were small purulent deposits; and on a longitudinal section of the femur being made, the bone was found perfectly healthy.

In the cases which precede this one, the inflammation had, to all appearance, begun in the synovial membrane of the joint; but the knee became in the present instance, as has been seen, secondarily affected, as a consequence of caries and necrosis occurring in the patella. This shows how readily 